\title{
RELATOS DE PAIS SOBRE A INCLUSÃO E A TRAJETÓRIA ESCOLAR DE FILHOS COM DEFICIÊNCIA INTELECTUAL
}

PARENTS REPORTS ABOUT SCHOOL INCLUSION AND TRAJECTORY OF CHILDREN WITH INTELLECTUAL DISABILITIES

\section{RELATOS DE LOS PADRES SOBRE LA INCLUSIÓN Y LA TRAYECTORIA DE HIJOS CON DISCAPACIDAD INTELECTUAL}

\author{
Gisele Roberta Coelho* \\ Juliane Ap. de Paula Perez Campos* \\ Priscila Benitez ${ }^{* * *}$
}

\begin{abstract}
RESUMO
O envolvimento dos pais na trajetória acadêmica dos filhos pode favorecer maior desempenho social e acadêmico deles, especialmente, filhos com deficiência intelectual (DI). Uma forma de propiciar esse envolvimento pode ser com base em informaçóes levantadas pelos pais em relação às trajetórias dos seus filhos. O objetivo foi caracterizar o processo de inclusão no percurso escolar de crianças com deficiência intelectual, a partir da percepção dos pais sobre a trajetória escolar dos seus filhos. Foi realizada uma entrevista semiestruturada com três pais de crianças com DI matriculados na escola regular, de modo a contemplar a trajetória escolar dos alunos com DI. A análise do discurso dos pais identificou a necessidade de um profissional para acompanhar a criança com DI, durante a realização das atividades acadêmicas na sala de aula, e o estabelecimento de uma parceria colaborativa entre a díade escola especial e regular. São propostas discussões sobre as práticas inclusivas identificadas, com base nos relatos dos pais.
\end{abstract}

Palavras-chave: Deficiência intelectual. Educação especial. Família. Inclusão escolar. Trajetória escolar.

\footnotetext{
Texto recebido em 21 de janeiro de 2014 e aprovado para publicação em 18 de abril de 2016.

Fonte de financiamento: este trabalho contou com bolsa de estudos de doutorado no ano de 2013, referente à terceira autora, concedido pela FAPESP (Processo n. ${ }^{\circ}$ 2010/16701-0).

* Graduada em Licenciatura em Educação Especial pela Universidade Federal de São Carlos (UFSCar). Endereço: Rua Capitão Manoel Alves Carneiro, 1330 - Boa Vista 1, São Carlos-SP, Brasil. CEP: 13575-002. E-mail: giseleroberta.ufscar@gmail.com.

* Doutora em Educação Especial pelo Programa de Pós-Graduação em Educação Especial - UFSCar, docente do Departamento de Psicologia da UFSCar. Endereço: Rua Arnaldo Victaliano, 1450, ap. 144, Ribeirão Preto-SP, Brasil. CEP: 14091-200. Telefone: (16) 99310-2784. E-mail: jappcampos@gmail.com.

** Doutora em Psicologia pelo Programa de Pós-Graduação em Psicologia da UFSCar, professora adjunta da Universidade Federal do ABC. Endereço: Rua do Agronegócios, 184, São Carlos-SP, Brasil. CEP: 13566-423. Telefone: (16) 98827-1426. E-mail: pribenitez@yahoo.com.br.
} 


\begin{abstract}
The involvement of parents in the academic life of their children can foster greater social and academic performance of their children, especially those with intellectual disabilities (ID). One way to facilitate this involvement may be from information gathered by the parents regarding the trajectories of their children. The objective was to characterize the inclusion process in the schooling of children with intellectual disabilities, from the perception of parents about the school life of their children. A semi-structured interview with three parents of children enrolled ID was held at regular school, in order to include the school trajectory of students with ID. The parents of discourse analysis identified the need for a professional to accompany the child with DI while conducting academic activities in the classroom, which allows us to reaffirm the importance of a specialist and the establishment of a collaborative interaction between special needs and regular school. They are proposed discussions on identified inclusive practices, based on parental reports.
\end{abstract}

Keywords: Intellectual disabilities. Especial education. Family. School inclusion. School trajectory.

\title{
RESUMEN
}

La participación de los padres en la vida escolar de sus hijos puede fomentar un mayor rendimiento social y académico de ellos, especialmente los niños con discapacidad intelectual (DI). Una forma de facilitar esta participación puede ser a partir de informaciones recogida por los padres con respecto a las trayectorias de sus hijos. El objetivo fue caracterizar el proceso de inclusión en la escolarización de los niños con discapacidad intelectual, a partir de la percepción de los padres sobre la vida escolar de sus hijos. Una entrevista semiestructurada con tres padres de niños con DI matriculados en la escuela regular, a fin de discutir la trayectoria escolar de los alumnos con DI. El análisis del discurso de los padres identificó la necesidad de un profesional para acompañar al niño con DI durante la realización de actividades académicas en el aula y el establecimiento de una colaboración entre la escuela especial y regular. Son propuestas discusiones sobre prácticas inclusivas identificadas, basadas en relatos de los padres.

Palabras-claves: Discapacidad intelectual. Educación especial. Familia. Inclusión escolar. Trayectoria escolar.

\section{INTRODUÇÃO}

anto a escola, como a família apresentam funções sociais, políticas e educacionais compartilhadas ao longo de todo o processo educacional do aprendiz (Rego, 2003). As duas instituições são responsáveis pela transmissão 
e construção do conhecimento desenvolvido em uma determinada cultura (Dessen \& Polonia, 2007). Após a implementação do Estatuto da Criança e do Adolescente (Lei n. ${ }^{\circ}$ 8.069, de 13 de julho de 1990), os pais e, ou, responsáveis assumiram a obrigatoriedade de matricular seus filhos na escola e, além disso, zelar pela frequência e aprendizagem (Moreira, Bedran, \& Carellos, 2011).

A escola e família são fontes educacionais distintas, uma vez que o ensino transmitido pela família apresenta caráter assistemático e informal, ao contrário, a escola, que apresenta instrução sistemática que visa à construção do conhecimento em etapas sequenciais de ensino (Dessen \& Polonia, 2007; Rego, 2003). Apesar de objetivos e funções diferentes, nota-se a importância da parceria compartilhada entre família e escola, no sentido de ambas buscarem estratégias conjuntas que beneficiem o processo educativo para todos os aprendizes (Dessen \& Polonia, 2007), especialmente, quando se trata do processo inclusivo de crianças com deficiência intelectual.

Atualmente, podem-se observar as conquistas obtidas para os aprendizes com deficiência intelectual (DI), ao longo de sua história social, visto que o conceito da DI passou por uma transformação constante, de acordo com o período histórico e cultural no qual estava inserido, desde um defeito mental, como proposto inicialmente por Tredgold em 1908 (como citado em Almeida, 2004), passando por um estado de desenvolvimento mental incompleto, posteriormente ao retardo mental até alcançar a nomenclatura deficiência mental e, nos dias atuais, DI. A American Association on Intellectual and Developmental Disabilities (AAIDD) considera, nos dias atuais, a DI como uma deficiência que envolve limitações no funcionamento intelectual e no comportamento adaptativo, expresso em habilidades conceituais, sociais e práticas, com início antes dos 18 anos (Almeida, 2004; Freitas \& Del Prette, 2010; Veltrone \& Mendes, 2012).

Em consonância com a transformação do conceito, são discutidas as possíveis prevençōes primárias, secundárias e terciárias, resultando no sistema de apoios para essa demanda, na perspectiva de contemplar práticas inclusivas na operacionalização desses apoios (Almeida, 2004). As práticas inclusivas, por sua vez, podem ser consideradas como uma ação política, cultural, social e pedagógica, em defesa do direito de todos os alunos aprenderem e participarem das atividades escolares, sem qualquer tipo de preconceito.

As políticas públicas em relação à educação inclusiva asseguram aos alunos currículo, métodos e recursos específicos para atender às suas necessidades (Brasil, 2008), de modo que, nesse escopo, torna-se ainda mais válido o envolvimento dos pais na vida escolar dos filhos, uma vez que tem sido particularmente relevante esse envolvimento no rendimento escolar dos filhos e na percepção que constroem suas perspectivas em relação à escola. 
Os pais, por sua vez, podem contribuir com o desenvolvimento e emprego de práticas inclusivas promissoras, a partir da parceria com a escola (Benitez \& Domeniconi, 2014). Direcionando essa discussão para o processo de inclusão escolar, muito se tem questionado sobre como os pais têm percebido e avaliado a trajetória escolar de filhos com DI. As experiências dos pais sobre esse processo dos seus respectivos filhos podem favorecer no arranjo de condições que possam maximizar oportunidades de aprendizagem para cada estudante.

Silveira e Neves (2006) aplicaram entrevistas e observações no ambiente escolar com pais de crianças com deficiência múltipla (que apresentavam DI), objetivando compreender como esses pais entendiam o processo de inclusão escolar e social de seus filhos. Os dados obtidos com essa investigação mostraram que os pais não identificaram aspectos promissores com a inclusão para os seus filhos, devido às condiçôes existentes na escola (turmas com um alto número de alunos matriculados e a formação dos professores para lidar com essa demanda). $\mathrm{E}$, além disso, os pais apontaram também o preconceito existente no ambiente da escola regular (Silveira \& Neves, 2006).

Luiz e Nascimento (2012) entrevistaram 11 mães e 1 pai de crianças com síndrome de Down, com o propósito de explorar as experiências das famílias no processo de transição da instituição especializada para a rede regular de ensino, com base em uma investigação de casos múltiplos. Os resultados mostraram a importância do acompanhamento de profissionais com as famílias ao longo de todo o processo de inclusão, com o propósito de auxiliar na adaptação do estudante ao novo espaço escolar, bem como as intervenções fornecidas a ele.

Com base nos dados de Luiz e Nascimento (2012) e Silveira e Neves (2006), um ponto que pode ser discutido refere-se às percepções apontadas pelos pais em relação ao processo de inclusão escolar de seus filhos e como tais percepções poderiam ser modificadas de modo a gerar práticas inclusivas promissoras para essa demanda, no ambiente da escola regular, com base em intervenções que favoreçam a participação dos pais no processo de ensino-aprendizagem dos estudantes com DI.

Um exemplo de intervenção com pais de crianças com DI, em relação ao processo inclusivo dos seus filhos, foi descrito por Benitez e Domeniconi (2014). Para a realização da intervenção, foi proposto que os pais aplicassem um conjunto de atividades de leitura e escrita, em suas residências, na presença da pesquisadora. De um total de 8 fases previstas para aplicação da atividade, os pais aplicaram, conforme o esperado, 7 fases. A dica oral, dada pelos pais para cada filho, foi uma característica similar entre todos eles. Em relação aos encaminhamentos, um ponto em comum entre três deles (de um total de cinco) 
foi lembrá-los de elogiar os comportamentos adequados de seus filhos durante a realização da atividade.

Pelo exposto, torna-se necessário problematizar e aprofundar os dados existentes na literatura sobre a percepção dos pais com filhos com DI, em relação ao processo de inclusão escolar dos seus filhos, de modo a sugerir intervenções ou capacitações posteriores que contribuam com a efetivação e o emprego de práticas inclusivas acadêmicas para essa demanda, com base na investigação da trajetória escolar dessas crianças, na ótica dos pais. Questiona-se sobre qual tem sido a trajetória escolar dessas crianças, pela percepção dos pais, de modo a compreender e caracterizar o processo de escolarização do aluno com DI na escola regular, por relatos específicos sobre o início da escolarização dos seus filhos, sobre a escola especializada, sobre a percepção geral dos pais, sobre a interação com os professores e a equipe pedagógica e a avaliação do processo de modo geral.

Esta proposta teve como objetivo específico caracterizar o processo de inclusão no percurso escolar de crianças com deficiência intelectual, pela percepção dos pais sobre a trajetória escolar dos seus filhos. Espera-se que este estudo possa contribuir na compreensão de como os pais percebem a inclusão dos seus filhos, de forma a acompanhar a realidade vivenciada e, futuramente, trazer intervenções direcionadas para a melhoria e aperfeiçoamento da trajetória de alunos com DI.

\section{MÉTODO}

\subsection{Abordagem da pesquisa}

Para atender às indagaçôes propostas que visaram ao conhecimento do percurso escolar de aprendizes com DI, pela percepção dos pais, utilizou-se da metodologia de natureza qualitativa, uma vez que essa abordagem atende às expectativas em relação à compreensão da realidade pesquisada, considerando, principalmente, a complexidade dos fenômenos sociais e educativos inseridos na problemática.

Trata-se do emprego de um delineamento com sujeito único, com o propósito de compreender a trajetória de cada estudante de modo individual, como uma pessoa que está inserida em um contexto social e atua diretamente neste.

\subsection{Aspectos éticos}

Esta pesquisa foi submetida para análise ao Comitê de Ética em Pesquisas e Seres Humanos da UFSCar e, somente após a aprovação do projeto (Parecer n. ${ }^{\circ}$ 382.863/CAEE 19247313.7.0000.5504), iniciou-se a coleta dos dados. 


\subsection{Seleção e caracterização dos participantes}

Para a seleção dos participantes, a pesquisadora entrou em contato com um grupo de pais que participavam de um projeto destinado à orientação de pais. Foi realizada uma reunião com os possíveis pais interessados em participar do estudo. Como critério de inclusão, os pais ou responsáveis deveriam ter, ao menos, um filho com deficiência intelectual que estivesse devidamente matriculado na rede pública e regular de ensino, com a faixa etária de 9 a 10 anos de idade (anos iniciais do ensino fundamental). Após a reunião, a responsável pelo grupo de pais obteve o aceite de três pais que atendiam aos critérios previamente estabelecidos: 1 pai (P1) e 2 mães (M2 e M3). O quadro 1 caracteriza os pais participantes e brevemente seus filhos.

Quadro 1. Caracterização dos pais participantes e de seus filhos

\begin{tabular}{|c|c|c|}
\hline Sigla & Descrição dos pais participantes & Descrição dos filhos \\
\hline P1 & $\begin{array}{l}\text { on, } 42 \text { anos, graduado em Engenharia de Produção, em uni- } \\
\text { versidade pública. Atualmente é responsável pelas tarefas de } \\
\text { casa. Tem dois filhos e convive com a esposa. A família apre- } \\
\text { senta um nível socioeconômico baixo. }\end{array}$ & $\begin{array}{l}\sigma^{*}, 9 \text { anos, diagnósti- } \\
\text { co: autismo }\end{array}$ \\
\hline M2 & $\begin{array}{l}\text { }, 39 \text { anos, com ensino fundamental incompleto. Atualmente } \\
\text { é dona de casa. Tem duas filhas e convive juntamente com o } \\
\text { esposo. A família apresenta nível socioeconômico baixo. }\end{array}$ & $\begin{array}{l}\text { \%, } 9 \text { anos, diagnósti- } \\
\text { co: deficiência intelec- } \\
\text { tual }\end{array}$ \\
\hline M3 & $\begin{array}{l}\text { } \text {, } 37 \text { anos, com ensino fundamental completo. Atualmente, } \\
\text { é dona de casa. Tem três filhos e convive juntamente com o } \\
\text { esposo. A família apresenta um nível socioeconômico baixo. }\end{array}$ & $\begin{array}{l}\text { \%, } 10 \text { anos, diagnós- } \\
\text { tico: deficiência inte- } \\
\text { lectual }\end{array}$ \\
\hline
\end{tabular}

Fonte: elaborado pelas autoras.

O diagnóstico dos aprendizes, apresentado pelos pais, foi fornecido por instituição especializada e realizado por uma equipe de profissionais composta por psicólogo, médico-psiquiatra, fonoaudiólogo, fisioterapeuta, terapeuta ocupacional e psicopedagogo.

\subsection{Local}

A coleta dos dados foi realizada em cada residência, situadas em uma cidade de médio porte do interior do Estado de São Paulo. 


\subsection{Instrumento e procedimento de coleta de dados}

Foi conduzida a aplicação de uma entrevista semiestruturada, baseada em um roteiro para investigar o percurso escolar de alunos com deficiência intelectual, na visão dos pais. O roteiro da entrevista semiestruturada foi organizado em três categorias previamente selecionadas, julgadas necessárias e significativas para alcançar os objetivos propostos para esta pesquisa.

Essas categorias foram definidas como:

a) início da escolarização dos filhos (questão: "Relate a trajetória escolar do seu filho desde a educação infantil até o momento em que ele se encontra");

b) escola especializada (questão: "O seu filho já foi matriculado na escola especial? Se afirmativo, conte sobre a participação do seu filho nesse processo educativo);

c) percepção geral dos pais, envolvendo a interação com os professores e a equipe pedagógica, bem como uma avaliação geral do processo e expectativas futuras, com base nas seguintes questôes sobre a interação: "Conte-me como era a sua interação com os professores. Como vocês, pais, veem a atuação da equipe pedagógica, os professores baseando-se nas condições de cada aluno, considerando as possibilidades socioafetivas, cognitivas e psicomotoras?"; questôes sobre avaliação: "Como você avalia o trabalho que está sendo desenvolvido até agora nas escolas? Em geral, como você avalia a inclusão escolar as crianças nas escolas comuns?"; questão sobre expectativa: "Quais as perspectivas em relação ao futuro escolar do seu filho(a)?”.

As entrevistas foram gravadas, transcritas e encaminhadas aos participantes para leitura e aprovação, e, se necessária, a inclusão de alguma informação. As entrevistas tiveram um tempo médio de dez minutos.

\subsection{Análise dos dados}

Após a transcrição, leituras e análise dos dados, estes foram organizados em três eixos temáticos, tendo como referência as questóes de pesquisa e objetivos propostos para o estudo: 
a) o início do processo de escolarização com o intuito de reconstruir esse processo conforme as lembranças dos pais;

b) a escola especial na escolarização de crianças com DI, na perspectiva dos pais;

c) percepção geral do processo inclusivo, com base em relatos sobre a interação com os profissionais presentes no espaço escolar (professores e equipe pedagógica) e avaliação geral do processo.

A Figura 1 demonstra o plano de análise das informaçōes obtidas com a aplicação da entrevista semiestruturada.

Figura 1. Plano de análise das informações obtidas com a aplicação do roteiro proposto durante a entrevista semiestruturada

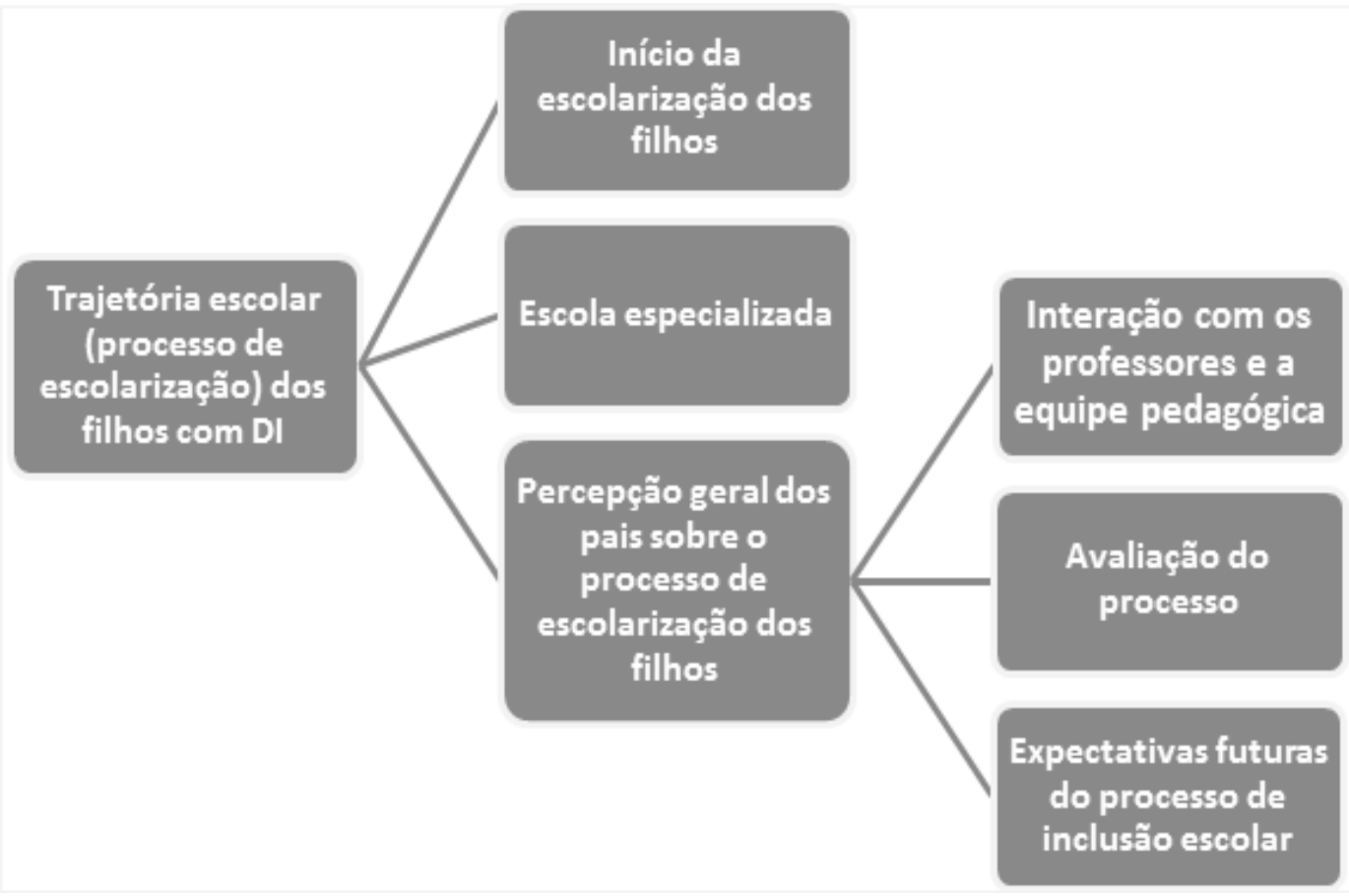

Fonte: elaborado pelas autoras.

\section{RESULTADOS E DISCUSSÃO}

Esta seção objetivou apresentar os relatos dos pais em relação ao processo de inclusão escolar dos filhos e discutir tais relatos com a literatura especializada da área. E, para isso, foi estruturado em três categorias de discussão de análise dos dados, conforme mencionado anteriormente. 


\subsection{Início do processo de escolarização dos filhos com DI}

No que concerne à ocorrência da trajetória escolar dos filhos, este item apresenta os relatos dos pais em relação ao início do processo de escolarização dos seus filhos. P1 e M2 relataram que seus filhos frequentaram a escola regular desde a educação infantil, enquanto M3 não respondeu à pergunta realizada: "Relate a trajetória escolar do seu filho desde a educação infantil até o momento em que ele se encontra”.

O Pedro começou com três meses na creche da universidade; ele estudava lá [...]. O Pedro sempre ficou na escola regular. Praticamente ele ficou um ano fora só porque a gente não tinha tutor aqui na escola municipal. Eu estou falando da escola regular, isso [...]. A partir que entra no primeiro ano que as crianças têm uma maturidade social que o Pedro não tem é a partir desse momento que ele precisa de um tutor (P1).

Eu acho que foi bom a ela. Tem esse problema dela desde o parquinho. No parquinho, tinha esse problema dela. Tinha dias que as crianças faziam desenho, e ela não fazia nada [...], só que agora pra gente ela está evoluindo; mas não é aquela evolução que a gente queria (M2).

Ah, normal! (M3).

Acredita-se na hipótese de que M3 possa ou não ter compreendido a pergunta. Como se trata de uma pergunta muito ampla, sugere-se a reformulação, no sentido de direcionar ainda mais a questão, por exemplo: "O que seria a trajetória normal? Como foi a escolarização na educação infantil? Como está sendo no ensino fundamental? Quais dificuldades?”.

Assim como P1 e M2 mostram, em suas falas, a dificuldade dos filhos no acompanhamento dos conteúdos acadêmicos na escola comum, M3 acredita que, mesmo sua filha demonstrando determinadas dificuldades provenientes da deficiência intelectual, considera a escolarização de sua filha como normal. Os relatos dos pais parecem corroborar os achados de Jacob e Loureiro (1996), no sentido de a criança com DI requerer apoios necessários para a condução do processo de ensino e aprendizagem, bem como os dados do estudo de Luiz e Nascimento (2012) com crianças com síndrome de Down.

Dessa forma, torna-se importante identificar os apoios necessários para a inclusão da criança com deficiência intelectual na escola regular, com base nos sistemas de apoios; desde apoios intermitentes, limitados, amplos até aqueles apoios permanentes, destinados a pessoas que necessitam de um apoio mais intenso e frequente (Almeida, 2004). 
Ademais, os relatos dos pais demonstram a dificuldade que apresentam para obter o sistema de apoio necessário para a efetiva inclusão escolar de seus filhos, especialmente, no período da educação infantil. Tais dificuldades também foram reveladas nos relatos de professores de educação infantil, quando entrevistados sobre a temática da inclusão de crianças com deficiência intelectual nessa modalidade, de acordo com o estudo de Vitta, Vitta e Monteiro (2010). Os professores apontaram que, em relação ao processo de aprendizagem, as crianças com deficiência intelectual apresentam maiores dificuldades para aprender, quando comparadas às crianças com deficiência física, além disso os professores ressaltaram a importância da formação continuada que envolva as diferentes deficiências e as necessidades educacionais decorrentes de cada uma.

Ao tratar ainda da trajetória escolar das três crianças investigadas neste estudo, na visão dos pais, um ponto em comum entre os três relatos foi a matrícula e participação de seus filhos, em algum momento, na escola especial.

\subsection{A escola especial na trajetória das crianças com DI}

As três crianças participantes do estudo, em algum momento de sua trajetória escolar, foram matriculadas na escola especial.

$\mathrm{Na}$ APAE, ele começou em 2010. Ele estava com 7, 8 anos e, a partir desse momento, ele frequenta todos os dias pela manhã, de manhã ele vai à APAE (P1).

Ela já evoluiu bem do que ela tava. A gente levou ela na APAE, e as moças falou que ela não tem necessidade de estudar aqui. Só que a gente levou no médico, fez um monte de exame, monte de papelada e ver na escola como vai ser a evolução dela (M2).

Ano passado, a Maria vai na APAE, e é muito cansativo ficar o dia inteiro. Aí ela não quer ir. Aí fui na escola pra conversar com a diretora. Ela autorizou a saída dela mais cedo (M3).

De acordo com os relatos, os pais têm visões diferenciadas do processo escolar de seus filhos na Associação de Pais e Amigos dos Excepcionais (APAE). P1 mencionou a participação de seu filho na instituição especializada como um processo construído diariamente no contraturno do período em que está matriculado na escola regular. Já M2 alega que não há necessidades de sua filha frequentar a instituição, pois, de acordo com seu relato, ao ser indicada para a avaliação na APAE, foi encaminhada apenas para a matrícula na escola regular, enquanto M3 relata o estresse e cansaço de a filha ter jornada dupla na rotina escolar. 
Os pais entrevistados por Luiz e Nascimento (2012) mostraram a importância da APAE como um local de acolhimento para refletirem sobre a inclusão escolar de seus filhos, visto que as famílias demonstraram sentimento de conforto, segurança e experiência com as particularidades das crianças que os profissionais da APAE demonstravam para lidar com os filhos. Botura (2011), Vilaronga e Mendes (2014) sugerem a importância de a escola especializada atuar em parceria colaborativa com a escola regular, de modo a estabelecer um diálogo que propicie condiçōes de aprendizagem direcionadas a cada aprendiz, com flexibilidade na carga horária e na frequência de participação das atividades. Tais informações poderiam servir como estratégia para M3 procurar auxílio de negociação da carga horária de sua filha, de modo a minimizar a carga horária e flexibilizar o processo ensino-aprendizagem, com o objetivo de não provocar o cansaço relatado pela mãe.

Outro ponto ressaltado no relato de M2 refere-se aos "exames médicos" realizados com sua filha para verificar se seria matriculada na APAE. Nesse contexto, coube uma discussão mais acurada sobre o diagnóstico das crianças participantes do estudo. Com a transcrição, foi possível resgatar que P1 ressaltou a dificuldade em estabelecer o diagnóstico de autismo de seu filho, M2 recuperou aspectos organicistas vinculados à investigação de deficiência intelectual em conjunto com sua filha, e, nas respostas de M3, não foi possível identificar relatos sobre o assunto discutido.

Um cuidado necessário, em relação ao diagnóstico, refere-se à transmissão da informação para os pais, visto que o impacto pode gerar dificuldades em sua aceitação. Nesse sentido, a informação transmitida e seu conteúdo são fundamentais no processo. De acordo com Petean e Murata (2000, p. 41), "É de suma importância à compreensão que os pais apresentam sobre as causas do problema e principalmente sobre as consequências advindas dele". Tal cautela se torna necessária para que se minimizem as dificuldades de aceitação de diagnóstico, como ocorreu com os pais do estudo de Silveira e Neves (2006), ao relatarem os sentimentos de tristeza, angústia, medo e insegurança diante do diagnóstico inicial. Atualmente, o diagnóstico de DI tem sido conduzido por uma equipe multiprofissional, de modo a valorizar as especificidades advindas do ambiente e da cultura de cada indivíduo, aferindo, além das habilidades intelectuais, as adaptativas (Almeida, 2004, 2012; Freitas \& Del Prette, 2010; Veltrone \& Mendes, 2012). 


\subsection{Percepção geral dos pais em relação ao processo de escolarização (trajetória) dos filhos}

Esse eixo de análise demonstra a percepção geral dos pais em relação à inclusão de seus filhos, de acordo com o cotidiano de cada um deles, pela interação com os professores e a equipe pedagógica, avaliação do processo e expectativas futuras sobre a inclusão dos seus filhos. A seguir, estão os relatos dos pais em relação a interação com os professores.

Nunca tive problema. É claro que, no começo, tem umas professoras que se assustam. Elas não são da educação especial, é professora da sala. O tutor, o Guilherme, ${ }^{1}$ é muito tranquilo. Elas se assustam um pouquinho. Teve uma que ficou com uma cara de raiva de "estou dando aula pra um autista”, mas não era uma aversão ao Pedro ou a gente, mas era dela mesmo se cobrando. Mas eu vou, converso muito com os professores [...] principalmente ela, que eu senti, na época, não foi essa atual, era anterior, eu senti que ela estava bastante assustada. Fui lá conversar com ela, falei: "Tenha calma, tem o Guilherme, tem a Joana que vem aqui. Então calma!”. A nossa preocupação maior era, até então, o Pedro ficar em contato social real. A escola é o que tem mais próximo da realidade que uma criança pode ter, escola regular. Agora que estamos conversando com o Guilherme, para o Pedro olhar mais pra lousa. Agora mudou de professora e, com essa nova professora, surgiu a ideia. Como ela escreve muito na lousa, ela escreve três palavras e seleciona, no início da aula, e pede para o Pedro ler (P1).

A gente não tem relação com professores de ir na escola conversar, só na reunião. A gente leva ela no reforço, mas não fala muita coisa, só fala que ela está indo bem, que ela leu dois texto sozinha (M2).

Não tem interação. Eu só converso com o Guilherme que é o professor, que dá atendimento especial, os outros professores não falo e não vejo (M3).

Os relatos dos pais sobre a interação com a equipe pedagógica são apresentados a seguir.

Há, sim, o afetivo. Boa vontade a gente sabe que não falta de todos, mas lidar com o autismo ninguém muito sabe não. É que a gente cobra da equipe, não é da equipe, falta um plano do governo, Secretaria da Educação, pra de fato inserir [...] Falta um plano efetivo de inclusão para o autismo. É muito diferente o autista, quando se estuda educação especial, congressista tudo aluno com Down, deficiência intelectual, mas o autismo é um caso à parte. $\mathrm{O}$ autismo requer um cuidado que é muito específico e não são preparados. Essa parte social de integrar a equipe é muito boa, que é o que a gente queria, mas o educacional, que é aprender a ler e escrever, não sabe, não está preparado. Boa vontade tem em todo mundo, a gente percebe afetivo então: o Pedro é carinhoso, e o pessoal é carinhoso com ele (P1).

1 Nome fictício atribuído ao professor de educação especial. 
Eu acho que ela ajuda bem [...]. Só que a gente não conversa muito, não tem relacionamento de conversa a gente quase não vê ele dá na sala de aula e não tem contato com ele. Só tem contato com a Joana, porque vem em casa (M2).

Converso com o Guilherme, que toda semana fica com ela, mas a diretora da escola eu nem conheço. Ano passado, a Maria foi à APAE, e é muito cansativo ficar o dia inteiro [...]. Aí ela não quer ir [...], aí fui na escola pra conversar com a diretora. Ela autorizou a saída dela, mas eu não vi ela (M3).

De acordo com a análise dos relatos dos pais, P1 é o pai que mais se destaca em relação à atuação em conjunto aos professores, no sentido de buscar a melhor formação para o filho, questionando as práticas educativas dos docentes e buscando a melhorias na educação para seu filho como um todo. Os dados de M2 e M3 refletem sobre a importância de obter maior comunicação com os professores de suas filhas.

A comunicação deveria ocorrer, independentemente do modo escrito ou oral, para que houvesse uma negociação entre os resultados obtidos e esperados do desempenho de cada estudante, com o propósito de fortalecer a relação entre escola-família (Bhering \& Siraj-Blatchford, 1999). Ademais, uma estratégia plausível nesse escopo seria o trabalho colaborativo entre pais, professores regulares e especiais como uma alternativa para fortalecer a relação entre famíliaescola (Benitez \& Domeniconi, 2014; Vilaronga \& Mendes, 2014).

No que concerne à interação entre os pais com a equipe pedagógica, as mães não demonstram clareza para expressar suas opiniões e, em especial, retratam pouco contato com a direção da escola. Porém P1 aponta para a falta de um plano específico de atuação pedagógica para as crianças com autismo, deixando implícitas as dificuldades na atuação educacional dos docentes, em relação ao processo de alfabetização de seu filho. Os dados de P1 dialogam com o proposto por Sanches e Oliveira (2011) em relação à importância de garantir o ensino de habilidades acadêmicas aos aprendizes incluídos na escola regular, além das habilidades socioemocionais.

Um ponto que merece destaque se refere à importância de instrumentalizar não apenas os professores e os pais, mas também a direção e coordenação escolar, de modo que a inclusão escolar seja compreendida como um processo social e complexo que envolve os diversos segmentos da sociedade, entre eles, os pais, os professores, a coordenação, a direção e a comunidade local (Benitez \& Domeniconi, 2014). Desse modo, propóe-se que estudos futuros vislumbrem a operacionalização de intervenções que garantam a interlocução entre os distintos agentes educacionais, de modo a propor melhorias no processo de inclusão 
escolar para cada uma das crianças incluídas.

De modo geral, foram apresentados os relatos dos pais no que concerne à percepção ampla que apresentam sobre o processo de inclusão escolar.

Não é bom, por isso que a gente teme a inclusão radical; eu e uns quinhentos pais da APAE, independente de ser autista ou qualquer outra necessidade especial. Convenhamos à escola regular dita regular já está mal com os alunos neurotípicos, ditos normal. Já está caótico, e ainda vai pôr um pessoal com necessidade especial em um lugar que está ruim (P1).

Pra mim, está sendo útil; ajuda bastante, mas era o começo que ela dizia que não podia ser a gente, que ela tem que ser autônoma, que ela tem que fazer. A gente foi, conversou com a diretora, levou todos os papéis da APAE, que ela tem essa dificuldade, ela não tem problema (M2).

Então tem hora que eu até falo assim: dá vontade de deixar ela só na APAE, mas, como a Joan ${ }^{2}$ fala que acha melhor, tirar ela da APAE e deixar só aqui (na escola regular), porque é complicado levar em duas escolas. E como a Maria não é especial, então à gente fica [...] É complicado mandar em duas escolas. Ela pega o ônibus 7 e meia [...], ela volta, corre, come algo pra voltar pra escola e, depois, às $16 \mathrm{~h}$, vai buscar novamente. Eu fico o dia inteiro atrás disso, esperando a hora de buscar. Por isso, às vezes, quero deixar fora da escola, mas a Joana sempre fala pra deixar nas duas (M3).

O relato de P1 demonstra a importância do trabalho conjunto entre a escola especial e regular, bem como o relato de M3. Todavia M3 demonstra a importância de um profissional especializado para auxiliá-la na tomada de decisão sobre em qual escolar deveria matricular a filha. Outro aspecto a considerar nessa forma de inclusão refere-se à quantidade de carga horária que o aluno é exposto nos dois turnos, de acordo especificamente com o relato de M3. Ademais, dois pais parecem não compreender as necessidades reais de seus filhos, o que pode contribuir para que o direcionamento de percepção de inclusão possa parecer equivocado. Abaixo seguem os relatos dos pais em relação à avaliação do percurso escolar dos filhos até o presente momento.

O social é dez, o educacional falta um pouco, fica a desejar. Se não fosse a Joana com o projeto dela, talvez o Pedro estivesse sem nenhuma instrução educacional até agora. E é bem específico, porque tem autista que, se você colocar na sala de aula e conseguir fazer ele ficar quieto, ele vai aprender a ler antes e até dar aula pro professor. No caso do Pedro, como ele tem esse déficit cognitivo, déficit de comunicação, perdão, ele não se comunica praticamente nada, ele não tem noção do que ele está fazendo na sala de aula. Como não está preparado pra isso, a escola não está preparada pra isso, a sociedade não está preparada pra isso. Exceto o que está na APAE ou em algumas escolas particulares que, no caso, em $\ldots$, não tem nenhuma $(\mathrm{P} 1)$.

2 Nome fictício atribuído à psicóloga que trabalha com sua filha. 
Pra mim, tá bom. Tá porque essa evolução que ela está tendo muito. Duro seria se ela não tivesse nem esse [...], porque a gente tá vendo a evolução dela e, antes, ela não tinha evolução nenhuma (M2).

Bom. Está se desenvolvendo cada vez que eu vou lá. O Guilherme fala que ela está melhorando, está se desenvolvendo, que ela está desenvolvendo (M3).

Ainda que os relatos de M2 e M3 não forneçam subsídios práticos que envolvam açóes concretas dos motivos que as levam a considerar como positivo o processo de inclusão escolar dos seus filhos, o relato de M3, no item anterior, sobre a percepção dos pais em relação ao processo de inclusão escolar, retoma a importância de um profissional especializado (como Joana, citado na fala anterior, e como Guilherme, citado neste excerto) para trabalhar com os aspectos de alfabetização do seu filho no âmbito regular, indo ao encontro dos relatos de M3 nos dados apresentados sobre a percepção geral dos pais em relação à inclusão dos seus filhos, na fala relacionada ao trabalho do professor de educação especial (como Guilherme).

No que se refere aos aspectos positivos vivenciados pelas famílias, de modo geral, de acordo com os relatos obtidos, destacam-se: a importância da equipe de profissionais presentes na escola regular, de acordo com o relato de P1 ("O positivo é que a gente vê dedicação das pessoas, pessoas que estão envolvidas. Eu tô falando da equipe fixa da escola. Professor regular mesmo é carinho, dedicação... O social é dez, o educacional [...]"), a evolução da filha de M2 ("A evolução que ela teve até agora") e no relato de M3 ("Bom. Está se desenvolvendo. Cada vez que eu vou lá, o Guilherme fala que ela está melhorando, está se desenvolvendo, que ela está desenvolvendo"), foi possível identificar parte do relato de P1, como a presença do feedback fornecido pelo professor de educação especial para ele, tal como parte do relato de M2, no que concerne ao desenvolvimento de sua filha.

As famílias parecem apontar para o desenvolvimento dos alunos e a forma carinhosa que são recebidos, corroborando os achados descritos por Luiz e Nascimento (2012) em relação à dedicação e experiência dos profissionais envolvidos na instituição. Outra análise que foi possível ser conduzida, com base nos relatos, refere-se às críticas apontadas pelos pais, em relação ao processo de inclusão escolar.

O que seria ideal é ter uma equipe multidisciplinar em cada escola, para lidar com esses casos especiais: psicólogo, pedagogo, terapeuta ocupacional, fisioterapeuta [...]. É por isso que a gente bate na secretária, a Secretaria da Educação. O governo Executivo, municipal, estadual, federal ouvir mais quem sabe lidar com o assunto e criar condiçôes de fato para essa inclusão, no caso do autista, sem falar naqueles outros que andam com sonda e são adolescentes e tem que trocar frauda a escola pública não está preparada para isso (P1). 
Eu acho que ela ajuda bem [...] Só que a gente não conversa muito, não tem relacionamento de conversa. A gente quase não vê. Ele dá na sala de aula e não tem contato (M2).

Aqui na escola, ela só fica meia hora com o Guilherme. Eu acho que deveria ter mais horas, mais dias ficar com o Guilherme, porque, do resto, ela fica “jogada” na classe (M3).

Os relatos demonstram as principais melhorias que poderiam ocorrer no âmbito da escola regular. P1 destaca a importância do trabalho em rede, em busca de apoios com os órgãos regulamentares, como a Secretaria de Educação, os governos municipais e estaduais, além de destacar a importância de uma equipe multidisciplinar em cada escola regular para trabalhar com cada aprendiz. M3 também destaca a importância do professor de educação especial com uma carga horária maior para atender sua filha e a inclusão de sua filha como aquela destinada apenas a inseri-la ao contexto de sala de aula, sem qualquer recurso ou apoio direcionado a ela. E M2 demonstra a dificuldade para conversar com os professores.

Os relatos emitidos por M3, em relação "à sua filha ficar jogada na classe”, vão ao encontro dos argumentos apresentados por Pimentel (2012), no sentido que não é suficiente garantir apenas o acesso à escola regular, "É necessário o apoio ao docente para que esta inclusão aconteça garantindo-se a equidade no atendimento pedagógico. Isso requer uma formação docente que envolva, para além do respeito, a compreensão da diversidade" (p. 141).

É necessário que haja uma equipe multidisciplinar para o acompanhamento dos alunos, além de se criarem as condições para favorecer um maior diálogo dos pais com a escola, pois, como previsto na Declaração de Salamanca, (Organização das Nações Unidas para a Educação, a Ciência e a Cultura [UNESCO], 1994, p. 2), é necessário que as escolas regulares "encorajem e facilitem a participação de pais, comunidades e organizações de pessoas portadoras de deficiências nos processos de planejamento e tomada de decisão concernentes à provisão de serviços para necessidades educacionais especiais". Os pais parecem demonstrar que estão atentos ao processo de inclusão, principalmente P1, o que leva a uma participação ativa na educação e formação de seu filho, requerendo em conjunto com os órgãos responsáveis a implantação de fato de uma inclusão na instituição do seu filho.

E, no que concerne às expectativas dos pais em relação ao futuro do processo de inclusão escolar, são apresentados os relatos dos pais.

O que eu sonho, quero ele implodindo logo. O que eu vejo, eu tenho impressão que ele tenha condição de chegar no colegial pra fazer colegial, mas a gente tem que quebrar, sentir fazer ele participar da sala de aula, e aí que tá, eu acho que vai demorar um tempo a mais (P1). 
Isso eu tenho bastante. É o que mais tem. Acho que ela vai passar a perna nos dois, ser melhor que os outros dois. Acho que ela não vai dar trabalho, porque o trabalho que ela está dando agora pra gente vai passar, mas ela tem mais vontade, ela é mais educada, respeita mais a gente. De noite, ela pede bênção. Às vezes, de noite, eu fico aqui sozinho, Ela quer fazer companhia. Totalmente diferente (M2).

Ah, porque é assim. Nosso futuro pertence a Deus. Só Deus sabe o que vai acontecer daqui meia hora (M3).

P1 e M2 acreditam na evolução do repertório acadêmico dos filhos, diferenciando-se de M3, que tem ideologia religiosa. Porém é o participante P1 que fala claramente do processo de inclusão, quando menciona a aspiração de que seu filho tenha acesso a uma escolarização regular, pelo menos até o ensino médio. Já as mães M2 e M3 expressam claramente suas aspirações quanto à inclusão escolar. Dessa forma, o apoio e a participação dos pais na vida escolar dos filhos colaboram com a escola no sentido de se obter um trabalho de classe mais equilibrado (Chechia \& Andrade, 2005; Moreira, Bedran, \& Carellos, 2011).

\section{CONSIDERAÇÕES FINAIS}

O principal objetivo deste trabalho foi caracterizar o processo de inclusão no percurso escolar de crianças com DI, com base na percepção dos pais sobre a trajetória escolar de seus filhos. E para isso foi proposta uma entrevista semiestruturada aplicada a três pais que tinham os filhos com DI, sendo estes matriculados na escola regular.

De modo geral, os resultados foram categorizados em três eixos de discussão (início do processo de escolarização dos filhos com DI, o papel da escola especializada e a percepção geral dos pais em relação ao processo inclusivo) e permitiram produzir uma síntese dos achados analisados. Uma primeira discussão se refere à necessidade de um profissional especializado que a criança com DI tem para o acompanhamento dos conteúdos acadêmicos na escola comum, de modo a auxiliar a criança com DI na realização das atividades acadêmicas na sala de aula comum. E, nessa configuração, o professor da sala de aula atuaria em parceria colaborativa com o profissional especializado, com o propósito de dialogar sobre as condições de aprendizagem direcionadas para cada aprendiz.

No que diz respeito à interação entre os diferentes profissionais presentes na escola, os pais sugeriram o estabelecimento de formas alternativas de comunicação com estes, a destacar a comunicação oral ou escrita no caderno do aluno. E, em relação à formação continuada dos profissionais, foi identificada a importância da instrumentalização de todos eles para trabalharem com a criança com DI. 
Outro ponto crítico se referiu à garantia dos sistemas de apoios (intermitentes, limitados, amplos e permanentes), além do estabelecimento de uma equipe multidisciplinar na escola regular para o acompanhamento de cada aluno, por meio do trabalho em rede, com apoio governamental (federal, estadual e municipal).

E, no que concerne ao estudante, uma discussão pertinente se referiu ao impacto da dupla jornada (entre escola especial e regular) no desempenho da criança e a importância de se criar flexibilidade na carga horária e na frequência de participação das atividades. E, por último, é importante destacar as dificuldades para elaboração do diagnóstico da DI.

Este estudo identificou certas limitações, como as perguntas realizadas e o número de participantes. Propõe-se que estudos futuros aprimorem a qualidade do tipo de pergunta a ser realizada aos pais.

Assim, mediante os resultados apresentados e as considerações expostas, é importante destacar que este trabalho não teve a pretensão de esgotar a temática investigada, mas propor reflexóes que possam servir de base para estudos futuros, que tenham como objetivo o desenvolvimento, a programação e operacionalização de intervenções em conjunto com os pais, de modo a favorecer a interação entre escola e família. 


\section{REFERÊNCIAS}

Almeida, M. A. (2004). Apresentação e análise das definições de deficiência. Revista de Educação, 6, 33-48.

Almeida, M. A. (2012). O caminhar da deficiência intelectual e classificação pelo sistema de suporte/apoio. In M. A. Almeida. (Org.), Deficiência intelectual: realidade e ação. (51-65). São Paulo: FDE.

Benitez, P. \& Domeniconi, C. (2014). Capacitação de agentes educacionais: proposta de desenvolvimento de estratégias inclusivas. Revista Brasileira de Educação Especial, 20(3), 371-386.

Bhering, E. \& Siraj-Blatchford, I. (1999). Envolvimento de pais: um modelo de troca e colaboração. Cadernos de Pesquisa, 106, 191-216.

Botura, R. R. (2011). Inclusão escolar: a articulação entre educação especial e o ensino regular por meio da atuação colaborativa. Colloquium Humanarum, 8, 676-682.

Brasil. (2008). Política nacional de educação especial na perspectiva da educação inclusiva. Brasília: Ministério da Educação, Secretaria de Educação Especial. Recuperado a partir de http://portal.mec.gov.br/seesp/arquivos/pdf/politica. pdf.

Checia, V. A. \& Andrade, A. S. (2005). O desempenho escolar dos filhos na percepção de pais de alunos com sucesso e insucesso escolar. Estudos de Psicologia, 10(3), 431-440.

Dessen, M. A. \& Polonia, A. C. (2007). A família e a escola como contextos de desenvolvimento infantil. Paideia, 17(36), 21-32.

Freitas, L. C. \& Del Prette, Z. A. P. (2010). Comparando autoavaliação e avaliação de professores sobre as habilidades sociais de crianças com deficiência mental. Interpersona, 4(2), 183-193.

Jacob, A. V. \& Loureiro, S. R. (1996). Desenvolvimento afetivo: o processo de aprendizagem e atraso escolar. Paideia, 10(11), 149-160.

Lei n. ${ }^{\circ}$ 8.069, de 13 de julho de 1990 (1990, 13 de julho). Dispõe sobre o Estatuto da Criança e do Adolescente. Diário Oficial da República Federativa do Brasil, Brasília. Recuperado a partir de http://www.planalto.gov.br/ ccivil_03/leis/L8069.htm. 
Luiz, F. M. R. \& Nascimento, L. C. (2012). Inclusão escolar de crianças com síndrome de down: experiências contadas pelas famílias. Revista Brasileira de Educação Especial, 18(1), 127-140.

Moreira, M. I. G., Bedran, P. M. \& Carellos, S. M. S. D. (2011). A família contemporânea brasileira em contexto de fragilidade social e os novos direitos das crianças: desafios éticos. Psicologia em Revista, 17(1), 161-180.

Organização das Nações Unidas para a Educação, a Ciência e a Cultura. (1994). Declaração de Salamanca: necessidades educativas especiais - NEE. Salamanca: Unesco.

Petean, E. B. L. \& Murata, M. F. (2000). Paralisia cerebral: conhecimento das mães sobre o diagnóstico e o impacto deste na dinâmica familiar. Paideia, 10(19), 40-46.

Pimentel, S. C. (2012). Formação de professores para a inclusão: saberes necessários e percursos formativos. In T. G. Miranda \& T. A. Filho Galvão, O professor e a educação inclusiva: formação, práticas e lugares. Salvador: Edufba. (pp. 139-158).

Rego, T. (2003). Memórias de escola: cultura escola e constituição de singularidades. Petrópolis: Vozes.

Sanches, A. C. G. \& Oliveira, M. A. F. (2011). Educação inclusiva e alunos com transtorno mental: um desafio interdisciplinar. Psicologia: Teoria e Pesquisa, 27 (4), 411-418.

Silveira, F. F. \& Neves, M. M. B. J. (2006). Inclusão escolar de crianças com deficiência múltipla: concepção de pais e professores. Psicologia: Teoria e Pesquisa, 22(1), 79-88.

Veltrone, A. A. \& Mendes, E., G. (2012). Impacto da mudança de nomenclatura de deficiência mental para deficiência intelectual. Educação em Perspectiva, 3(2), 359-373.

Vilaronga, C. A. R. \& Mendes, E. G. (2014). Ensino colaborativo para o apoio à inclusão escolar: práticas colaborativas entre os professores. Revista Brasileira de Educação, 95(239), 139-151.

Vitta, F. C. F., Vitta, A. \& Monteiro, A. S. R. (2010). Percepção de professores de educação infantil sobre a inclusão da criança com deficiência. Revista Brasileira de Educação Especial, 16(3), 415-428. 